common in boys and may cause deviant behaviour and severe psychological problems. Most of these boys do not require extensive endocrinological investigations, which may be misleading as a result of transient growth hormone insufficiency, but they do urgently need treatment for their delay in growth and puberty. ${ }^{4}$ Both oxandrolone and growth hormone produced acceleration of growth in boys with constitutional delay of growth and puberty without any difference in testicular volumes.

This increased height velocity is not a placebo effect ${ }^{2}$ nor can it be attributed to the boys' own spontaneous growth spurt, as this does not occur until a testicular volume of $12 \mathrm{ml}$ is reached. ${ }^{6}$ Only three of the boys receiving oxandrolone and two of those receiving r-hGH had testicular volumes of $12 \mathrm{ml}$ or more at the end of the year of follow up. The significant difference in height velocity increment between oxandrolone and growth hormone could be the result of the sustained effect of oxandrolone previously noted. ${ }^{1-3}$ It is certainly not that oxandrolone triggers the pubertal growth spurt, as both groups had similar testicular volumes of $(10 \mathrm{ml})$ at the end of the study. There was therefore no difference in the speed of the progression through puberty between the two groups.

We consider that growth hormone is not indicated for the management of delay in the onset of the pubertal component of the human growth curve, but whether longer periods of treatment (more than one year) with growth hormone in constitutional delay of growth and puberty would increase eventual height is still in question.

A Buyukgebiz was visiting research fellow from the University of Ankara. The study was supported by Kabipeptides, Stockholm.

1 Stanhope R, Brook CGD. Oxandrolone in low dose for constitutional delay of growth and puberty in boys. Arch Dis Child 1985;60:379-81.

2 Stanhope R, Buchanan CR, Fenn GC, Preece MA. Double blind placebo controlled trial of low dose oxandrolone in the treatment of boys with constitutional delay of growth and puberty. Arch Dis Child 1988;63:501-5.

3 Clayton PE, Shalet SM, Price DA, Addison GM. Growth hormone responses to oxandrolone in boys with constituhormone responses to oxandrolone in boys with constitu-
tional delay of growth and puberty (CDGP). Clin Endocrinol tional delay of grow

4 Eastman CJ, Lazarus L, Stuart MC, Casey JH. The effect of puberty on growth hormone secretion in boys with short stature and delayed adolescence. Aust NZ F Med 1971;1: $154-9$

5 Bierich JR. Treatment of constitutional delay of growth and adolescence with human growth hormone. Klin Padiatr 1986;195:309-16

6 Tanner JM. Growth at adolescence. Oxford: Blackwell, 1962.

\title{
Endotracheal compared with intravenous administration of atropine
}

\author{
R F Howard, R $M$ Bingham
}

\begin{abstract}
Endotracheal and intravenous administration of atropine were compared in two groups of 10 children. No differences were found between the groups in effect on heart rate or speed of onset of the effect. We conclude that the two methods are equally effective.
\end{abstract}

Giving drugs by the endotracheal route has been recommended for use in resuscitation when venous access is not immediately available. ${ }^{1}$ Atropine, adrenaline, and lignocaine have all been given in this way. ${ }^{2} 3$ Most of the supporting data come from animal studies, but recently doubt has been expressed about the plasma concentrations achieved in adults after drugs have been given by the endotracheal route. ${ }^{4} \mathrm{We}$ therefore investigated the effect of atropine given in this way to children, measuring changes in the heart rate after a bolus dose.

Department of

Anaesthesia,

Sick Children,

Great Ormond Street,

London WC1N 3JH

R F Howard

R M Bingham

Correspondence to:

Dr Bingham.

Accepted 8 November 1989

\section{Patients and methods}

Twenty children aged between 1 and 8 years undergoing routine anaesthesia that required endotracheal intubation and neuromuscular blockade (for peripheral orthopaedic or urological operations) were studied. Informed consent was obtained and the children were randomly allocated to receive either atropine $25 \mu \mathrm{g} / \mathrm{kg}$ (diluted to $2 \mathrm{ml}$ with $0.9 \%$ saline) intravenously and $2 \mathrm{ml} 0.9 \%$ saline endotracheally, simultaneously, or atropine $50 \mu \mathrm{g} / \mathrm{kg}$ (diluted to $2 \mathrm{ml}$ with $0.9 \%$ saline) endotracheally and $2 \mathrm{ml} 0.9 \%$ saline intravenously, simultaneously. Neostigmine $(50 \mu \mathrm{g} / \mathrm{kg}$ ) was given six minutes later to reverse the effect of the neuromuscular blockage.

Heart rate was monitored continuously using an electrocardiograph (Simonsen and Weel DS521) and recorded on a two channel paper chart recorder for 12 minutes after the atropine had been given. The endotracheal solution was given with a standard $2 \mathrm{ml}$ syringe without adaptation and was followed by five manual hyperinflations of the chest. The intravenous solution was given through an indwelling cannula in the hand or arm.

Table 1 Comparability of the groups. Values are expressed as mean (SEM) except where otherwise stated

\begin{tabular}{lcc}
\hline & $\begin{array}{l}\text { Intravenous } \\
\text { group }(n=10)\end{array}$ & $\begin{array}{l}\text { Endotracheal } \\
\text { group }(n=10)\end{array}$ \\
\hline F:M ratio & $4: 6$ & $5: 5$ \\
Age (years) & $4(0 \cdot 8)$ & $3 \cdot 4(0 \cdot 9)$ \\
Weight (kg) & $15 \cdot 8(2 \cdot 3)$ & $15 \cdot 4(2 \cdot 5)$ \\
\hline
\end{tabular}


Table 2 Analysis of heart rate changes and time to maximum heart rate changes. Values expressed as mean (SEM)

\begin{tabular}{lcrc}
\hline & Intravenous group $(n=10)$ & Endotracheal group $(n=10)$ & $p$ Value \\
\hline Baseline heart rate (bpm) & $127 \cdot 3(9 \cdot 0)$ & $121 \cdot 4(9 \cdot 6)$ & 0.4 \\
Maximum change in heart rate & $36 \cdot 7(5 \cdot 5)$ & $31 \cdot 3(5 \cdot 7)$ & $0 \cdot 5$ \\
Percentage maximum change in heart rate & $30 \cdot 2(7 \cdot 1)$ & $32 \cdot 8(7 \cdot 3)$ & $0 \cdot 8$ \\
Time to maximum change (secs) & $135(13 \cdot 6)$ & $165(17 \cdot 5)$ & $0 \cdot 2$ \\
\hline
\end{tabular}

The data were analysed by Student's $t$ test, and a probability of $<0.05$ was accepted as significant.

\section{Results}

The groups were comparable for sex, age, and weight (table 1). For each patient the efficacy of the atropine was assessed by the increase in pulse rate, the percentage change from baseline, and the time taken for maximum effect. In none of these categories were the groups significantly different (table 2).

\section{Discussion}

Although the endotracheal route is recommended for giving some of the drugs used in resuscitation, ${ }^{1}$ there is conflicting evidence about its efficacy. ${ }^{2-4}$ In this study, endotracheal atropine resulted in a tachycardia that was clinically and statistically indistinguishable from that found when the drug was given intravenously.

Because both groups were given endotracheal fluid we were concerned that any tachycardia associated with mechanical stimulation should not confuse that caused by the vagolytic effect of the atropine. We think that this was unlikely for three reasons. Firstly, the size and timing of the changes in heart rate were similar in both groups. If the tachycardia in the endotracheal group was solely the result of mechanical stimulation it would be shorter and less pronounced than in the intravenous group. Secondly, a small initial tachycardia was seen in both groups after the endotracheal fluid had been given. This was followed by a longer, sustained rise in heart rate. Thirdly, there was no bradycardia after the neostigmine had been given to reverse the muscle relaxant six minutes later.

The method of administration was designed to simulate that most likely to be used in an emergency. The drug was given directly from a plain syringe, and five manual inflations of the chest were carried out to disperse it. We used the dose recommended by the Resuscitation Council, which is twice the normal intravenous dose. Delivery of the drug from the tip of the endotracheal tube using a catheter has been described in most previous reports. ${ }^{3-6}$ Although more reliable delivery of the total dose of the drug is likely to be achieved, we felt that this method was unlikely to be used in an emergency.

A number of previous studies have examined blood concentrations of drugs after endotracheal administration. In animal studies low initial plasma concentrations with prolonged duration of action have been found, and it has been suggested that a reservoir effect in the lung may explain this. ${ }^{5}$

The blood concentration achieved will also be influenced by several other factors, including the dose, dilution volume, and cardiac output. All our patients had normal cardiac function, whereas during resuscitation cardiac output is likely to be low. In dogs after cardiac arrest ${ }^{2}$ or with hypoxia induced bradycardia ${ }^{6}$ the endotracheal route was found to be as effective as the intravenous route. Conversely, in adults after cardiac arrest, low blood concentrations were found after adrenaline was given endotracheally, although the same dose was used for both the intravenous and endotracheal routes. ${ }^{4}$

It is not possible to predict the effect of low cardiac output on absorption from the lungs from our study, and further work is required.

In conclusion, $50 \mu \mathrm{g} / \mathrm{kg}$ (diluted to $2 \mathrm{ml}$ ) of atropine given endotracheally is as effective as $25 \mu \mathrm{g} / \mathrm{kg}$ given intravenously in children with normal cardiac function.

1 Resuscitation Council (United Kingdom). Resuscitation for the citizen. London: Department of Anaesthetics, The Royal Postgraduate Medical School, 1984.

2 Redding JS, Asuncion JS, Pearson JW. Effective routes for drug administration during cardiac arrest. Anesth Analg 1967;46:253-8.

3 Powers RD, Donowitz LG. Endotracheal administration of emergency medication. South Med F 1984;77:340-1.

4 Quinton DN, O'Byrne G, Aitkenhead AR. Comparison of endotracheal and peripheral intravenous adrenaline in cardiac arrest. Is the endotracheal route reliable? Lancet 1987 i:828-9.

5 Prete MR, Hannan CJ, Burkle FM. Plasma atropine concentrations via intravenous, endotracheal, and intraosseous administration. Am $\mathcal{J}$ Emerg Med 1987;5:101-4.

6 Elam JO. The intrapulmonary route for CPR drugs. In: Safar $\mathrm{P}$, ed. Advances in cardiopulmonary resuscitation. New York, Springer-Verlag, 1977:132. 